\title{
Thiazide-Associated Hyponatremia, Report of the Hyponatremia Registry: An Observational Multicenter International Study
}

\author{
Volker Burst ${ }^{\mathrm{a}} \quad$ Franziska Grundmann $^{\mathrm{a}}$ Torsten Kubacki ${ }^{\mathrm{c}} \quad$ Arthur Greenberg $^{\mathrm{e}}$ \\ Ingrid Becker $^{b}$ Despina Rudolf ${ }^{d}$ Joseph Verbalis ${ }^{f}$ \\ ${ }^{a}$ Department II of Internal Medicine and Center for Molecular Medicine, ${ }^{b}$ Institute of Medical Statistics, Informatics \\ and Epidemiology, University of Cologne, Cologne, 'Department of Rheumatology, Immunology and Nephrology, \\ Asklepiosklinik Hamburg Altona, Hamburg, ${ }^{d}$ Otsuka Pharma GmbH, Frankfurt, Germany; ${ }^{e}$ Duke University Medical \\ Center, Durham, NC, and ${ }^{\mathrm{f} G e o r g e t o w n}$ University Medical Center, Washington DC, USA
}

\section{Keywords}

Euvolemic hyponatremia $\cdot$ Thiazide $\cdot$ Thiazide-induced hyponatremia $\cdot$ Syndrome of inappropriate antidiuretic hormone secretion

\begin{abstract}
Background: Hyponatremia is a frequent and potentially life-threatening adverse side effect of thiazide diuretics. This sub-analysis of the Hyponatremia Registry database focuses on current management practices of thiazide-associated hyponatremia (TAH) and compares differences between TAH and syndrome of inappropriate antidiuretic hormone secretion (SIADH). Methods: We analyzed 477 patients from 225 US and EU sites with euvolemic hyponatremia $\left(\left[\mathrm{Na}^{+}\right] \leq 130\right.$ $\mathrm{mEq} / \mathrm{L}$ ) who were receiving a thiazide diuretic. Of these, 118 met criteria for true thiazide-induced hyponatremia $(\mathrm{TIH})$. Results: Thiazide was withdrawn immediately after hyponatremia was diagnosed only in $57 \%$ of $\mathrm{TAH}$; in these patients, the median rate of $\left[\mathrm{Na}^{+}\right]$change $\left(\Delta_{\text {daily }}\left[\mathrm{Na}^{+}\right]\right)$was significantly higher than those with continued thiazide treatment (3.8 [interquartile range: 4.0 ] vs. 1.7 [3.8] mEq/L/day). The most frequently employed therapies were isotonic saline (29.6\%), fluid restriction (19.9\%), the combination of these two (8.2\%), and hypertonic saline (5.2\%). Hypertonic saline produced
\end{abstract}

\section{KARGER}

E-Mail karger@karger.com www.karger.com/ajn
(C) 2017 The Author(s)

Published by S. Karger AG, Basel

This article is licensed under the Creative Commons AttributionNonCommercial-NoDerivatives 4.0 International License (CC BYNC-ND) (http://www.karger.com/Services/OpenAccessLicense). Usage and distribution for commercial purposes as well as any distribution of modified material requires written permission. the greatest $\Delta_{\text {daily }}\left[\mathrm{Na}^{+}\right](8.0[6.4] \mathrm{mEq} / \mathrm{L} /$ day $)$ followed by a combination of fluid restriction and normal saline (4.5 [3.8] $\mathrm{mEq} / \mathrm{L} /$ day) and normal saline alone (3.6 [3.5] mEq/L/day). Fluid restriction was markedly less effective $(2.7[2.7] \mathrm{mEq} / \mathrm{L} /$ day). Overly rapid correction of hyponatremia occurred in $3.1 \%$ overall, but in up to $21.4 \%$ given hypertonic saline. Although there are highly significant differences in the biochemical profiles between TIH and SIADH, no predictive diagnostic test could be derived. Conclusions: Despite its high incidence and potential risks, the management of TAH is often poor. Immediate withdrawal of the thiazide is crucial for treatment success. Hypertonic saline is most effective in correcting hyponatremia but associated with a high rate of overly rapid correction. We could not establish a diagnostic laboratory-based test to differentiate TIH from SIADH.

(C) 2017 The Author(s)

Published by S. Karger AG, Basel

\section{Introduction}

Since their introduction in 1957, thiazide-type diuretics have been widely in use for the management of arterial hypertension [1] and are one of the most frequently prescribed drugs today. However, their use has risks, and thiazides can induce potentially life-threatening hyponatremia. The true

Volker Burst, MD

Department II of Internal Medicine and Center for Molecular Medicine University Hospital Cologne, Kerpener Str. 62

DE-50937 Cologne (Germany)

E-Mail volker.burst@uk-koeln.de 
epidemiology of thiazide-induced hyponatremia (TIH) is unknown and published analyses rather focus on patients with thiazide-associated hyponatremia (TAH), that is, hyponatremia and co-incident treatment with a thiazide diuretic but without proven causality. Recent estimates note TAH incidences from 4 to $14 \%$ [2-4], and even up to $30 \%$ [5], in patients prescribed thiazide diuretics. A recent population-based cohort study including 13,325 individuals has shown that exposure to thiazides is associated with an almost 5 times higher risk for hyponatremia [6]. Furthermore, Olsson et al. found that in the emergency room setting, as many as $17 \%$ of all cases of hyponatremia [7] were associated with a thiazide diuretic-containing medication. Advanced age, female gender, and low body mass index have been identified as risk factors for hyponatremia in thiazide-treated patients $[4,6,8]$. Usually, hyponatremia ensues within days after the initiation of treatment and the average time from initiation to diagnosis was calculated to be 19 days in a recent meta-analysis [9], but onset can be delayed by months $[10,11]$. True TIH seems to be doseindependent and probably occurs only in a susceptible subpopulation of patients. In these individuals, it has been shown that rechallenging with only a single dose of a thiazide can lead to a prompt drop of serum sodium within hours $[10,12]$. However, at present, it is not possible to identify subjects at risk for TIH before commencing the therapy.

The mechanisms leading to TIH involve increased water intake $[12,13]$, diminished $\mathrm{NaCl}$ reabsorption at the distal tubule diluting site, and/or impaired water excretion. The latter is evoked by vasopressin-independent enhancement of water permeability of the inner medullary collecting duct $[14,15]$ as well as by cation depletion which, in turn, leads to vasopressin-mediated water reabsorption [16]. Recent work by Frenkel et al. [13] suggests that polydipsia and reduced urea excretion may be the driving force for developing TIH rather than vasopressinor aquaporin 2-dependent mechanisms.

Our current knowledge about the clinical characteristics of TIH (or TAH) mainly stems from case reports and small case series comprising a total of approximately 150 patients. According to these sources, the majority of patients appear clinically euvolemic and typically present with biochemical features of extracellular fluid volume expansion, that is, low or low-normal serum creatinine and serum uric acid, and urine sodium concentration greater than $20 \mathrm{mEq} / \mathrm{L}$ [17-20]. This similarity with the typical picture of the syndrome of inappropriate antidiuretic hormone secretion (SIADH), the most frequent cause of hyponatremia, makes it difficult to distinguish these two disorders on clinical or biochemical grounds.

Thiazide-Associated Hyponatremia
Recommended treatment strategies include withdrawal of the drug and electrolyte repletion, or administration of hypertonic saline in severe cases. Water restriction with or without concomitant administration of normal saline or normal saline alone are also commonly used therapies. However, the absolute and relative effectiveness of these measures has never been studied systematically and the current use of these treatment options is not known. Furthermore, since the exact proportion of true TIH is unclear, all TAH patients are typically treated uniformly as TIH patients, which may lead to unnecessary permanent thiazide withdrawal in at least some cases.

In summary, $\mathrm{TAH}$ is a frequently encountered situation that constitutes a major challenge for the physician with regard to both diagnostic and therapeutic management. Furthermore, to date, there are no clinical trials comparing TIH and SIADH, which are the 2 most prevalent etiologies of euvolemic hyponatremia, with regard to diagnostic or treatment strategies.

The multinational hyponatremia Registry (NCT01240668) was initiated to prospectively assess the current state of treatment of euvolemic and hypervolemic hyponatremia in diverse real-world hospital settings in the United States and the European Union (EU). More specifically, the Registry was designed to determine which diagnostic and treatment modalities are currently employed, how effective they are, and how rapidly and reliably they result in an increase in serum $\left[\mathrm{Na}^{+}\right]$. This analysis comprises the clinically important group of patients with TAH, defined here as patients who were enrolled as having euvolemic hyponatremia as assessed by the treating physician and who would otherwise be considered to have SIADH (in a protocol-defined adjudication process performed by A. Greenberg and J. Verbalis) had they not been treated with a thiazide diuretic. To our knowledge, this is the largest prospective study of the management of TAH and the only study comparing TAH and SIADH. Moreover, we assessed differences in the clinical and biochemical profiles between the more rigorously defined subgroup of TIH and SIADH.

\section{Materials and Methods}

\section{Study Plan}

The study design has been described previously in detail [21, 22]. The study protocol was approved by individual IRB at each participating institution, and informed consent (or waiver) was obtained prior to data collection. Patients with euvolemic or hypervolemic hyponatremia were enrolled from 146 US sites and 79 EU sites. The study was exclusively observational; no standardized diagnostic or treatment protocols were imposed. Determination of volume status was done solely by the treating physicians.

Am J Nephrol 2017;45:420-430

DOI: 10.1159/000471493 


\section{Inclusion and Exclusion Criteria}

Only patients with clinically meaningful hyponatremia $\left(\left[\mathrm{Na}^{+}\right]\right.$ $\leq 130 \mathrm{mEq} / \mathrm{L}$ ) were enrolled. Patients were excluded if they were less than 18 years old, hypovolemic, severely hyperglycemic, or receiving renal replacement therapy. A complete listing of inclusion and exclusion criteria has been published previously [21, 22].

\section{Adjudication}

Data from patients who met a prespecified review threshold were subject to adjudication as previously described. A substantial number of patients initially diagnosed with euvolemic hyponatremia by the treating physician had to be excluded because of clinical or biochemical findings suspicious for hypovolemia or because they received thiazide or thiazide-like diuretics. The latter group constitutes the primary analysis group of TAH patients for the present paper. For further refinement, we sought to identify cases with true TIH by subjecting the TAH dataset to a computerized step-wise algorithm, which led to the exclusion of all subjects in which: (1) the thiazide was never withdrawn; (2) serum $\left[\mathrm{Na}^{+}\right]$did not increase by at least $3 \mathrm{mEq} / \mathrm{L}$ in 1 day or $5 \mathrm{mEq} / \mathrm{L}$ in 2 days after thiazide withdrawal, respectively; (3) the serum $\left[\mathrm{Na}^{+}\right]$decreased again by a minimum of $3 \mathrm{mEq} / \mathrm{L}$ after initial resolution of hyponatremia without recommencement of the thiazide; (4) serum $\left[\mathrm{Na}^{+}\right]$increased by at least $3 \mathrm{mEq} / \mathrm{L}$ while the thiazide was not yet withdrawn. Finally, 3 authors (2 nephrologists [V.B. and A.G.], and one endocrinologist [J.V.]) reviewed the remaining cases independently using all information entered into the Registry; only those cases that were identified as TIH by all experts concordantly were assigned to the TIH group.

Of the 5,028 patients enrolled in the Registry between September 2010 and February 2013, 2,847 patients had been enrolled as having euvolemic hyponatremia. After adjudication, 1,597 of the per-protocol data set were confirmed to have euvolemic hyponatremia and most (95\%) of these were diagnosed clinically as having SIADH (1,524). The TAH group comprised 477 patients, and the TIH subgroup encompassed 118 patients (online suppl. Fig. 1; for all online suppl. material, see www.karger.com/ doi/10.1159/000471493).

\section{Definitions and Statistical Methods}

For categorizing $\left[\mathrm{Na}^{+}\right]$, mild hyponatremia was defined as $\left[\mathrm{Na}^{+}\right] \leq 130 \mathrm{mEq} / \mathrm{L}$ but $>125 \mathrm{mEq} / \mathrm{L}$, moderate hyponatremia as $\left[\mathrm{Na}^{+}\right] \leq 125 \mathrm{mEq} / \mathrm{L}$ but $\geq 120 \mathrm{mEq} / \mathrm{L}$, and severe hyponatremia as $\left[\mathrm{Na}^{+}\right]<120 \mathrm{mEq} / \mathrm{L}$. Overly rapid correction of $\left[\mathrm{Na}^{+}\right]$was defined per protocol as an increase $>12 \mathrm{mEq} / \mathrm{L}$ in any 24 -h interval or $>18$ $\mathrm{mEq} / \mathrm{L}$ in any 48 -h interval, consistent with limits commonly recommended at the time the protocol was designed. As the primary measure of effectiveness, the average daily rate of $\left[\mathrm{Na}^{+}\right]$change $\left(\Delta_{\text {daily }}\left[\mathrm{Na}^{+}\right]\right)$over the entire treatment episode was calculated as the total increment in $\left[\mathrm{Na}^{+}\right]$during the treatment period divided by the number of treatment days. For patients who received no treatment, the interval during which the patient was hyponatremic was used. Since rapid treatment success, that is, within the first day after diagnosis, is important especially in severe hyponatremia, we also assessed median $\left[\mathrm{Na}^{+}\right]$increase within the first $24 \mathrm{~h}$ after treatment initiation $\left(\Delta_{24 \mathrm{~h}}\left[\mathrm{Na}^{+}\right]\right)$. Hyponatremia treatments classified as active included fluid restriction, normal or hypertonic saline, loop diuretics, salt tablets, and tolvaptan.

Group comparisons were done by chi-square tests for categorical variables and Mann-Whitney U or Kruskal-Wallis tests for quantitative variables. OR with 95\% CIs discriminating SIADH and
Table 1. Baseline demographics and clinical characteristics

\begin{tabular}{lccc}
\hline Parameter & $\begin{array}{l}\text { SIADH } \\
(n=1,524)\end{array}$ & $\begin{array}{l}\text { TAH } \\
(n=477)\end{array}$ & $\begin{array}{l}\text { TIH } \\
(n=118)\end{array}$ \\
\hline $\begin{array}{l}\text { Age, } n(\%), \text { years } \\
\quad 50\end{array}$ & $186(12)$ & $21(4)$ & $4(3)$ \\
$\quad 51-64$ & $373(25)$ & $98(21)$ & $23(20)$ \\
$\quad 65-74$ & $339(22)$ & $108(23)$ & $29(25)$ \\
$\quad \geq 75$ & $626(41)$ & $250(52)$ & $62(53)$ \\
Age years, median (IQR) & $71(22)$ & $75(19)$ & $75(17)$ \\
Gender & & & \\
$\quad$ Male & $695(46)$ & $139(29)$ & $31(26)$ \\
Prior HN, $n(\%)$ & $407(27)$ & $68(14)$ & $8(7)$ \\
$\quad$ Yes & $430(28)$ & $157(33)$ & $36(31)$ \\
$\quad$ Unknown & & & \\
HN at admission, $n(\%)$ & $1,252(82)$ & $418(88)$ & $114(97)$ \\
$\quad$ Yes & $19(1)$ & $6(1)$ & $1(1)$ \\
$\quad$ Unknown & &
\end{tabular}

SIADH vs. TAH $p$ values: median age $<0.001$; sex $<0.001$.

SIADH vs. TIH $p$ values: median age $=0.003$; sex $<0.001$.

TAH (excluding TIH; $n=359$ ) vs. TIH $p$ values: median age $=$ 0.99 ; gender 0.43 .

TIH were calculated by univariate logistic regression. Multivariate logistic regression analysis was performed to identify useful parameters for discriminating SIADH and TIH. Significant baseline characteristics and empirically derived ratios of selected parameters were included in the modeling. Treatment success was evaluated by logistic regression, including the co-factor therapy. Overall success to control hyponatremia was assessed categorically by calculating the rate of reaching several clinically relevant correction benchmarks for the entire initial therapy episode: $\Delta\left[\mathrm{Na}^{+}\right] \geq 5 \mathrm{mEq} / \mathrm{L}$, achievement of $\left[\mathrm{Na}^{+}\right]>130 \mathrm{mEq} / \mathrm{L}$, and normalization of $\left[\mathrm{Na}^{+}\right]$, that is, $\geq 135 \mathrm{mEq} / \mathrm{L}$. Analysis of tolvaptan cases was limited to descriptive statistics due to low numbers. For post-hoc, pairwise comparisons, the exact Fisher test was used. $p$ values were not adjusted for multiple comparisons, and a $p<0.05$ was considered significant. Analyses were executed with IBM SPSS Statistics version 23.

\section{Results}

From the 477 TAH patients, 165 (35\%) were classified as mild, 148 (31\%) as moderate, and $164(34 \%)$ as severe cases of hyponatremia. In 381 patients (80\%), hydrochlorothiazide was the most commonly used thiazide diuretic, followed by bendroflumethiazide $(34 ; 7 \%)$, and the thiazide-like diuretics chlorthalidone (23; 5\%), indapamide (19; 4\%), and metolazone $(5 ; 1 \%)$.

Comparison of patient demographics and clinical characteristics are shown in Table 1. Compared to the SIADH group, patients with TAH or TIH were signifi- 
cantly older ( $p<0.001$ and $p=0.003$, respectively) and more likely to be female $(p<0.001)$. Hyponatremia was present at hospital admission in $88 \%$ of those with TAH and $97 \%$ with TIH and previous hyponatremia episodes had been reported in only a minority of cases.

Proper diagnostic work-up of hyponatremia includes assessment of the so-called Schwartz-Bartter criteria, that is, serum and urinary osmolality and urinary sodium, as well as TSH and cortisol. The complete set of these recommended tests were performed only in $22 \%$ of TAH patients; in $15 \%$, none of these parameters was obtained (online suppl. Table 1), and these were rates similar to those in the SIADH group.

Given the reported similarity between TIH and SIADH, we compared biochemical baseline characteristics of the TIH and SIADH groups (Table 2). In addition, exploratory analysis of empirically derived ratios to amplify the predictive power of single parameters was performed. In summary, these analyses revealed several highly significant differences in the biochemical profiles of TIH and SIADH as shown in Table 2. TIH patients showed significantly lower serum $\left[\mathrm{Na}^{+}\right]$, serum $\left[\mathrm{K}^{+}\right]$, serum osmolality, urine $\left[\mathrm{Na}^{+}\right]$, urine osmolality, $\mathrm{TSH}$, urine osmolality:blood urea nitrogen (BUN) ratio, urine osmolality:serum creatinine ratio, urine $\left[\mathrm{Na}^{+}\right]$:serum creatinine ratio, urine $\left[\mathrm{Na}^{+}\right]: \mathrm{BUN}$ ratio, urine $\left[\mathrm{Na}^{+}\right]$:serum uric acid ratio, urine osmolality:serum uric acid ratio, and serum $\left[\mathrm{K}^{+}\right]$:serum uric acid ratio, while BUN, serum uric acid, and BUN:serum creatinine ratio were significantly higher compared to these values in SIADH patients. Figure 1 shows the odds ratios of some of these parameters demonstrating that various categories can be identified, which clearly favor one diagnosis over the other. However, we were unable to derive a valid diagnosis-predicting model using the multivariate logistic regression analysis. Of note, the biochemical profiles of the TIH and the TAH group were remarkably similar.

In TAH patients, the thiazide should be promptly stopped according to current recommendations. However, the immediate discontinuation of the thiazide $(<1$ day), was done only in $57 \%$ of TAH patients; $30 \%$ were kept on the drug throughout the entire episode and in $13 \%$, the withdrawal was delayed by several days (on average 3 days). In 9 (2\%) TAH patients, the thiazide was restarted before discharge after temporarily withholding it. The rate of thiazide cessation correlated with the severity of hyponatremia; immediate withdrawal was reported in 29,68 , and $76 \%$ of patients with mild, moderate, and severe hyponatremia, respectively. The majority (89\%) of TAH patients who were subject to prompt thiazide dis-

Thiazide-Associated Hyponatremia continuation were also treated with at least one active anti-hyponatremia therapy, while this was the case in only $76 \%$ of those who were maintained temporarily or permanently on the thiazide medication.

Overall, 85 (17.8\%) patients in the TAH group, mostly mild cases $(67 \%)$, did not receive any active therapy and in only $38 \%$ of those the thiazide was withdrawn. The most frequently used initial active treatments (online suppl. Table 2) were isotonic saline (NS; 29.6\%) fluid restriction (FR; 19.9\%), the combination of FR and NS (FR + NS; $8.2 \%)$, and hypertonic saline (HS; 5.2\%). Less frequently applied treatment options included the combination of NS and loop diuretic (4.2\%), the combination of FR and HS (3.8\%), and salt tablets (2.3\%), whereas only $4(0.8 \%)$ patients received tolvaptan.

Comparison of the effectiveness of frequently applied therapies in TAH and SIADH is shown in Table 3. Overall, the median daily rate of $\left[\mathrm{Na}^{+}\right]$change $\left(\Delta_{\text {daily }}\left[\mathrm{Na}^{+}\right]\right)$as well as the median $\left[\mathrm{Na}^{+}\right]$increase within the first $24 \mathrm{~h}$ after treatment initiation $\left(\Delta_{24 \mathrm{~h}}\left[\mathrm{Na}^{+}\right]\right)$was significantly higher in the immediate withdrawal group than in the group with delayed or no withdrawal $(p<0.001)$ with 3.8 (interquartile range: 4.0 ) vs. $1.7(3.8) \mathrm{mEq} / \mathrm{L} /$ day and 6.0 (6.0) vs. 3.0 (6.0) mEq/L, respectively. However, significantly more number of cases of overly rapid correction were seen when the thiazide was stopped early (4.6 vs. $1 \% ; p=0.029$ ).

Not surprisingly, the median baseline serum $\left[\mathrm{Na}^{+}\right]$in the no-treatment group was higher $(128 \mathrm{mEq} / \mathrm{L})$ than in the NS $(122 \mathrm{mEq} / \mathrm{L})$, the FR $(121 \mathrm{mEq} / \mathrm{L})$, or the HS $(117$ $\mathrm{mEq} / \mathrm{L}$ ) group. When treatment consisted of immediate withdrawal only, that is, no other therapy was employed, a modest but highly significant effect compared to no or delayed withdrawal was seen with a $\Delta_{\text {daily }}\left[\mathrm{Na}^{+}\right]$of $2.0(4.0)$ vs. $0.4(1.0) \mathrm{mEq} / \mathrm{L} /$ day $(p=0.01)$ and a $\Delta_{24 \mathrm{~h}}\left[\mathrm{Na}^{+}\right]$of 3.0 (9.0) vs. $1.0(4.0) \mathrm{mEq} / \mathrm{L}(p=0.03)$. Adding any active therapy to drug withdrawal enhanced the effectiveness considerably. Conversely, for each applied active therapy, the impact on $\left[\mathrm{Na}^{+}\right]$increase was found to be the most pronounced when the thiazide was discontinued immediately. The most profound effect was observed with the use of HS in combination with early drug discontinuation yielding a $\Delta_{\text {daily }}\left[\mathrm{Na}^{+}\right]$and $\Delta_{24 \mathrm{~h}}\left[\mathrm{Na}^{+}\right]$of $8.0(6.4) \mathrm{mEq} / \mathrm{L} /$ day and $11.0(4.8) \mathrm{mEq} / \mathrm{L}$, respectively. NS alone and the combination NS + FR were similarly effective with a $\Delta_{\text {daily }}\left[\mathrm{Na}^{+}\right]$of $3.6(3.5) \mathrm{mEq} / \mathrm{L} /$ day and $4.5(3.8) \mathrm{mEq} / \mathrm{L} /$ day as well as a $\Delta_{24 \mathrm{~h}}\left[\mathrm{Na}^{+}\right]$of $6.0(6.0) \mathrm{mEq} / \mathrm{L}$ and $5.5(7.3)$ $\mathrm{mEq} / \mathrm{L}$, respectively. FR alone was markedly less effective with a $\Delta_{\text {daily }}\left[\mathrm{Na}^{+}\right]$and $\Delta_{24 \mathrm{~h}}\left[\mathrm{Na}^{+}\right]$of $2.7(2.7) \mathrm{mEq} / \mathrm{L} /$ day and $3.5(6.0) \mathrm{mEq} / \mathrm{L}$, respectively (all numbers given for

Am J Nephrol 2017;45:420-430 DOI: $10.1159 / 000471493$ 
Table 2. Baseline biochemical parameters

\begin{tabular}{|c|c|c|c|c|c|c|}
\hline \multirow[t]{2}{*}{ Parameter } & \multicolumn{2}{|c|}{ SIADH $(n=1,524)$} & \multicolumn{2}{|c|}{ TAH $(n=477)$} & \multicolumn{2}{|c|}{$\mathrm{TIH}(n=118)$} \\
\hline & number & median (IQR) & number & $\begin{array}{l}\text { median } \\
\text { (IQR) }\end{array}$ & number & $\begin{array}{l}\text { median } \\
\text { (IQR) }\end{array}$ \\
\hline Serum $\left[\mathrm{Na}^{+}\right], \mathrm{mEq} / \mathrm{L}$ & 1,524 & $124(8.0)^{1,2}$ & 477 & $122(10)$ & 118 & $120(8)^{3}$ \\
\hline Serum $\left[\mathrm{K}^{+}\right], \mathrm{mEq} / \mathrm{L}$ & 1,509 & $4.2(0.8)^{1,2}$ & 475 & $3.8(0.8)$ & 117 & $3.7(0.8)$ \\
\hline Serum creatinine, $\mathrm{mg} / \mathrm{dL}$ & 1,476 & $0.70(0.32)^{1,2}$ & 472 & $0.81(0.35)$ & 116 & $0.80(0.27)^{3}$ \\
\hline $\mathrm{BUN}, \mathrm{mg} / \mathrm{dL}$ & 1,265 & $12.4(8.1)^{1,2}$ & 401 & $15.1(10.1)$ & 100 & $14.0(7.0)$ \\
\hline BUN:creatinine ratio & 1,257 & $16.7(9.6)^{1,2}$ & 399 & $17.0(8.6)$ & 99 & $17.5(8.2)$ \\
\hline Urine $\mathrm{Na}^{+}, \mathrm{mEq} / \mathrm{L}$ & 750 & $72.0(61.0)^{1,2}$ & 216 & $50.0(54.0)$ & 71 & $45.0(49.0)$ \\
\hline Urine $\mathrm{K}^{+}, \mathrm{mEq} / \mathrm{L}$ & 350 & $31.0(27.3)$ & 131 & $30.0(32.6)$ & 50 & $29.0(33.0)$ \\
\hline Serum osmolality, mOsm/kg & 807 & $259(18)^{1,2}$ & 253 & $257(18)$ & 78 & $254(17)$ \\
\hline Urine osmolality, mOsm/kg & 797 & $404(266)^{1,2}$ & 239 & $335(226)$ & 72 & $316(199)^{3}$ \\
\hline Serum uric acid, $\mathrm{mg} / \mathrm{dL}$ & 315 & $2.8(1.8)^{1,2}$ & 97 & $4.1(2.5)$ & 35 & $4.2(2.5)$ \\
\hline Cortisol, $\mathrm{nmol} / \mathrm{L}$ & 385 & $441(330)^{1}$ & 125 & $513(363)$ & 45 & $486(385)$ \\
\hline $\mathrm{TSH}, \mathrm{mU} / \mathrm{L}$ & 739 & $1.60(1.94)^{2}$ & 251 & $1.48(1.93)$ & 78 & $1.21(1.77)$ \\
\hline Exploratory analyses & & & & & & \\
\hline $\begin{array}{l}\text { Urine osmolality: BUN ratio, } \\
\text { mOsm*dL/kg*mg }\end{array}$ & 685 & $36.1(29.6)^{1,2}$ & 206 & $23.9(20.7)$ & 63 & $20.4(16.8)^{3}$ \\
\hline Urine osmolality:serum creatinine & & & & & & \\
\hline ratio $\mathrm{mOsm} * \mathrm{dL} / \mathrm{kg}^{*} \mathrm{mg}$ & 787 & $566(518)^{1,2}$ & 238 & $420(367)$ & 72 & $402(311)$ \\
\hline $\begin{array}{l}\text { Urine }\left[\mathrm{Na}^{+}\right] \text {: serum creatinine ratio, } \\
\mathrm{mEq} / \mathrm{mg}\end{array}$ & 743 & $9.7(11.6)^{1,2}$ & 216 & $6.1(7.3)$ & 71 & $5.7(7.4)$ \\
\hline Urine $\left[\mathrm{Na}^{+}\right]: \mathrm{BUN}$ ratio, $\mathrm{mEq} / \mathrm{mg}$ & 656 & $0.6(0.72)^{1,2}$ & 187 & $0.38(0.4)$ & 63 & $0.29(0.3)$ \\
\hline $\begin{array}{l}\text { Urine }\left[\mathrm{Na}^{+}\right] \text {: serum uric acid ratio, } \\
\mathrm{mEq} / \mathrm{mg}\end{array}$ & 209 & $2.4(3.3)^{1,2}$ & 71 & $1.2(1.7)$ & 29 & $0.8(1.5)$ \\
\hline $\begin{array}{l}\text { Urine osmolality: serum uric acid ratio, } \\
\text { mOsm*dL/kg*mg }\end{array}$ & 211 & $143(146)^{1,2}$ & 68 & 77 (79) & 27 & $72.3(69.0)$ \\
\hline $\begin{array}{l}\text { Serum }\left[\mathrm{K}^{+}\right] \text {: serum uric acid ratio, } \\
\mathrm{mEq} / \mathrm{mg}\end{array}$ & 315 & $0.15(0.1)^{1,2}$ & 97 & $0.09(0.06)$ & 35 & $0.09(0.07)$ \\
\hline
\end{tabular}

BUN, blood urea nitrogen; $\left[\mathrm{K}^{+}\right]$, potassium concentration; TSH, thyroid stimulating hormone.

${ }^{1} p<0.05$ for SIADH vs. TAH.

${ }^{2} p<0.05$ for SIADH vs. TIH.

${ }^{3} p<0.05$ for TIH vs. TAH (excluding TIH).

Precise $p$ values: SIADH vs. TAH: $p<0.001$ for serum $\left[\mathrm{Na}^{+}\right]$, serum $\left[\mathrm{K}^{+}\right]$, serum creatinine, $\mathrm{BUN}$, urine $\left[\mathrm{Na}^{+}\right]$, urine osmolality, serum uric acid, urine osmolality: $\mathrm{BUN}$ ratio, urine osmolality:creatinine ratio, urine $\left[\mathrm{Na}^{+}\right]$:serum creatinine ratio, urine $\left[\mathrm{Na}^{+}\right]: \mathrm{BUN}$ ratio, urine $\left[\mathrm{Na}^{+}\right]$:serum uric acid ratio, urine osmolality:serum uric acid ratio, serum $\left[\mathrm{K}^{+}\right]$:serum uric acid ratio; $p=0.024$ for BUN:creatinine ratio; $p=0.031$ for serum osmolality; $p=0.008$ for cortisol; no significance for $\mathrm{TSH}$, urine [ $\mathrm{K}^{+}$]. SIADH vs. TIH: $p<0.001$ for serum $\left[\mathrm{Na}^{+}\right]$, serum $\left[\mathrm{K}^{+}\right], \mathrm{BUN}$, urine $\left[\mathrm{Na}^{+}\right]$, urine osmolality, serum uric acid, urine osmolality:BUN ratio, urine osmolality:creatinine ratio, urine $\left[\mathrm{Na}^{+}\right]$:serum creatinine ratio, urine $\left[\mathrm{Na}^{+}\right]: \mathrm{BUN}$ ratio, urine $\left[\mathrm{Na}^{+}\right]$:serum uric acid ratio, urine osmolality:serum uric acid ratio, serum $\left[\mathrm{K}^{+}\right]$:serum uric acid ratio; $p=0.03$ for BUN:creatinine ratio; $p=0.01$ for serum osmolality; $p=0.02$ for TSH; $p=0.05$ for serum creatinine; no significance for urine $\left[\mathrm{K}^{+}\right]$, cortisol. TAH (excluding TIH) vs. TIH: $p<0.001$ for serum $\left[\mathrm{Na}^{+}\right]$; $p=0.002$ for serum creatinine; $p=0.021$ for urine osmolality; $p=0.032$ for urine osmolality:BUN ratio; no significance for serum $\left[\mathrm{K}^{+}\right], \mathrm{BUN}, \mathrm{BUN}: \mathrm{creatinine}$ ratio, urine $\left[\mathrm{Na}^{+}\right]$, urine $\left[\mathrm{K}^{+}\right]$, serum osmolality, serum uric acid, cortisol, TSH, urine osmolality:creatinine ratio, $\left[\mathrm{Na}^{+}\right]:$serum creatinine ratio, urine $\left[\mathrm{Na}^{+}\right]: B U N$ ratio, urine $\left[\mathrm{Na}^{+}\right]$:serum uric acid ratio, urine osmolality:serum uric acid ratio, serum $\left[\mathrm{K}^{+}\right]$:serum uric acid ratio.

the immediate withdrawal group). At least in cases of mild and moderate hyponatremia, thiazide withdrawal alone is often viewed as appropriate therapy. However, with a $\Delta_{\text {daily }}\left[\mathrm{Na}^{+}\right]$of $0.6(3.4) \mathrm{mEq} / \mathrm{L}$, this cannot be confirmed in our dataset $(n=23)$. Likewise, the use of active therapies (NS, FR, FR + NS, HS; $n=109$ ) without withdrawing the thiazide also showed only low effectiveness with a $\Delta_{\text {daily }}\left[\mathrm{Na}^{+}\right]$of $1(3) \mathrm{mEq} / \mathrm{L}$.

The administration of HS was associated with a high rate of overly rapid correction with $21 \%$ in the withdraw- 


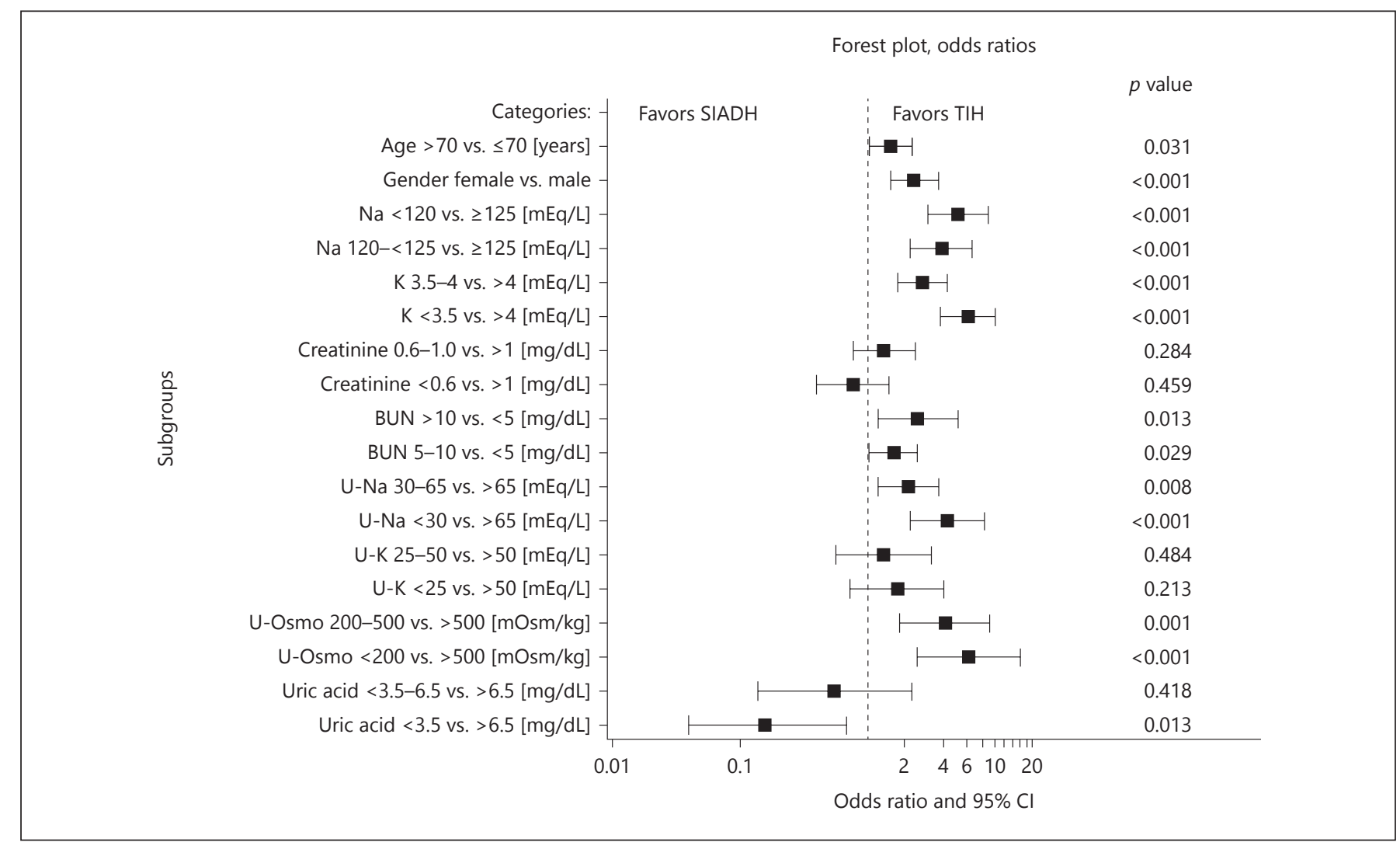

Fig. 1. Differential diagnosis of SAIDH vs. TIH. ORs and 95\% CIs for clinical and biochemical parameters calculated by univariate logistic regression.

al group, and $11 \%$ in the no/delayed withdrawal group. No cases of overly rapid correction were reported with the use of FR, irrespective of whether the thiazide diuretic was discontinued. On the other hand, with NS, the overly rapid correction rate was 5 and $2 \%$ for the thiazide withdrawal and no/delayed withdrawal group, respectively.

Of note, the $\Delta_{\text {daily }}\left[\mathrm{Na}^{+}\right]$and $\Delta_{24 \mathrm{~h}}\left[\mathrm{Na}^{+}\right]$were significantly greater in $\mathrm{TAH}$ patients than in the SIADH group irrespective of the chosen active treatment $(p<0.05$ at least) as long as the thiazide had been withdrawn immediately. This inter-group difference was largely mitigated when the thiazide medication was continued.

We assessed the success rate for achieving a clinically relevant $\left(\Delta_{24 \mathrm{~h}}\left[\mathrm{Na}^{+}\right] \geq 5 \mathrm{mEq} / \mathrm{L}\right)$ but safe $\left(\Delta_{24 \mathrm{~h}}\left[\mathrm{Na}^{+}\right] \leq 12\right.$ $\mathrm{mEq} / \mathrm{L}$ ) $\left[\mathrm{Na}^{+}\right]$increment (Fig. 2). In the logistic regression model, both immediate withdrawal and use of an active therapy were significant factors $(p=0.018$ and $p=$ 0.001 , respectively). HS in combination with immediate thiazide withdrawal showed the highest success rate (71\%) reaching statistical significance in pairwise comparison with all other therapies except HS and no/delayed withdrawal, NS and immediate withdrawal, and FR + NS with or without withdrawal. For the less effective therapies, FR + NS, NS, FR, and no active therapy, the influence of early thiazide discontinuation became increasingly albeit not significantly important for success rates (immediate withdrawal/no or delayed withdrawal) of $46 / 40$, $51 / 40,38 / 26$, and $33 / 11 \%$, respectively. Ineffectiveness of treatment, defined as a $\Delta_{24 \mathrm{~h}}\left[\mathrm{Na}^{+}\right]$between -2 and $2 \mathrm{mEq} / \mathrm{L}$ occurred most often with no therapy and FR, while treatment failure, defined as a $\left[\mathrm{Na}^{+}\right]$decrease of more than $2 \mathrm{mEq} / \mathrm{L}$ in the first $24 \mathrm{~h}$ was seen most often with no therapy (online suppl. Fig. 2).

Logistic analysis of correction benchmarks revealed both factors, withdrawal/no or delayed withdrawal and choice of therapy as independent factors for success $(p<$ $0.001)$ for achieving a $\Delta\left[\mathrm{Na}^{+}\right] \geq 5 \mathrm{mEq} / \mathrm{L}$ or a $\left[\mathrm{Na}^{+}\right]>130$ $\mathrm{mEq} / \mathrm{L}$ (for normalization of $\left[\mathrm{Na}^{+}\right]: p=0.774$ for the withdrawal group, $p<0.001$ for therapy). Of note, especially with respect to the benchmark $\Delta\left[\mathrm{Na}^{+}\right] \geq 5 \mathrm{mEq} / \mathrm{L}$, treatment effectiveness was markedly better in the TAH group than in the SIADH group (online supple. Fig. 3 ). 
Table 3. Effectiveness and overcorrection of $\mathrm{HN}$ therapy options in TAH and SIADH patients

\begin{tabular}{|c|c|c|c|c|c|c|}
\hline TAH & Patients, $n$ & $\begin{array}{l}\text { Median baseline } \\
{\left[\mathrm{Na}^{+}\right](\mathrm{IQR})} \\
\mathrm{mEq} / \mathrm{L}\end{array}$ & $\begin{array}{l}\text { Median rate } \\
\text { of }\left[\mathrm{Na}^{+}\right] \\
\text {change, (IQR), } \\
\mathrm{mEq} / \mathrm{L} / \text { days }\end{array}$ & $\begin{array}{l}{\left[\mathrm{Na}^{+}\right] \text {change (IQR) }} \\
\text { in first } 24 \mathrm{~h}, \mathrm{mEq} / \mathrm{L}\end{array}$ & $\begin{array}{l}\text { Median duration } \\
\text { of } \mathrm{Rx} \text { (IQR), days }\end{array}$ & $\begin{array}{l}\text { Overly rapid } \\
\text { correction, } \\
n(\%)\end{array}$ \\
\hline \multicolumn{7}{|l|}{ All therapies } \\
\hline TAH overall & 457 & $122(10)$ & $3.0(4.2)$ & $4.0(7.0)$ & $2(3)$ & $14(3.1)$ \\
\hline Immediate withdrawal & 259 & $120(9)$ & $3.8(4.0)$ & $6.0(6.0)$ & $2(2)$ & $12(4.6)$ \\
\hline Delayed or no withdrawal & 198 & $126(8)$ & $1.7(3.8)$ & $3.0(6.0)$ & $3(4)$ & $2(1.0)$ \\
\hline SIADH & 1,524 & $123(9)$ & $1.5(3.6)$ & $3.0(5.2)$ & $2(3)$ & $155(10.2)$ \\
\hline \multicolumn{7}{|l|}{ No active therapy } \\
\hline TAH overall & 76 & $128(5)$ & $0.6(2.1)$ & $2.0(4.3)$ & $4(3)$ & $1(1.3)$ \\
\hline Immediate withdrawal & 29 & $124(7)$ & $2.0(4.0)$ & $3.0(9.0)$ & $4(2)$ & $1(3.4)$ \\
\hline Delayed or no withdrawal & 47 & $129(3)$ & $0.4(1.0)$ & $1.0(4.0)$ & $5(3)$ & 0 \\
\hline SIADH & 170 & $127(5)$ & $0.4(1.0)$ & $2.0(4.5)$ & $7(8)$ & $4(2.4)$ \\
\hline \multicolumn{7}{|l|}{ Isotonic saline } \\
\hline TAH overall & 136 & $122(10)$ & $3.1(3.8)$ & $5.0(6.0)$ & $2(2)$ & $5(3.7)$ \\
\hline Immediate withdrawal & 79 & $121(9)$ & $3.6(3.5)$ & $6.0(6.0)$ & $2(2)$ & $4(5.1)$ \\
\hline Delayed or no withdrawal & 57 & $124(10)$ & $2.0(4.7)$ & $4.0(6.0)$ & $2(2)$ & $1(1.8)$ \\
\hline SIADH & 343 & $123(8)$ & $1.5(3.6)$ & $2.0(5.0)$ & $1(1)$ & $22(6.4)$ \\
\hline \multicolumn{7}{|l|}{ Fluid restriction } \\
\hline TAH overall & 93 & $121(8)$ & $2.3(3.3)$ & $2.0(6.0)$ & $3(2)$ & 0 \\
\hline Immediate withdrawal & 53 & $120(8)$ & $2.7(2.7)$ & $3.5(6.0)$ & $3(2)$ & 0 \\
\hline Delayed or no withdrawal & 40 & $122(6)$ & $1.9(2.9)$ & $2.0(7.0)$ & $3(3)$ & 0 \\
\hline SIADH & 393 & $123(7)$ & $1.0(2.2)$ & $2.0(5.0)$ & $3(5)$ & $30(7.6)$ \\
\hline \multicolumn{7}{|l|}{$\mathrm{FR}+\mathrm{NS}$} \\
\hline TAH overall & 39 & $120(5)$ & $4.5(5.2)$ & $5.0(8.0)$ & $1(1)$ & $1(2.6)$ \\
\hline Immediate withdrawal & 28 & $120(5)$ & $4.5(3.8)$ & $5.5(7.3)$ & $1(1)$ & $1(3.6)$ \\
\hline Delayed or no withdrawal & 11 & $120(5)$ & $5.0(6.0)$ & $4.0(7.0)$ & $1(0)$ & 0 \\
\hline SIADH & 112 & $121(7)$ & $2.4(3.6)$ & $2.0(5.0)$ & $2(1)$ & $16(14.3)$ \\
\hline \multicolumn{7}{|l|}{ Hypertonic saline } \\
\hline TAH overall & 23 & $117(7)$ & $5.3(6.8)$ & $8.0(6.0)$ & $1(3)$ & $4(17.4)$ \\
\hline Immediate withdrawal & 14 & $115(6)$ & $8.0(6.4)$ & $11.0(4.8)$ & $1(2)$ & $3(21.4)$ \\
\hline Delayed or no withdrawal & 9 & $121(7)$ & $4.3(3.5)$ & $5.0(2.0)$ & $3(5)$ & $1(11.1)$ \\
\hline SIADH & 49 & $120(8)$ & $3.1(6.3)$ & $5.0(8.5)$ & $2(2.5)$ & $11(17.4)$ \\
\hline \multicolumn{7}{|l|}{ Tolvaptan } \\
\hline TAH overall (individual values) & 4 & & & & & \\
\hline Immediate withdrawal & 2 & 128,129 & $8.0,0.5$ & $8.0,1.0$ & 1,4 & $0(0)$ \\
\hline Delayed or no withdrawal & 2 & 114,125 & $8.0,4.0$ & $8.0,8.0$ & 1,2 & $0(0)$ \\
\hline SIADH & 83 & $125(8)$ & $4.3(7.4)$ & $7.0(10.0)$ & $1(2)$ & $21(25.3)$ \\
\hline
\end{tabular}

p-values $<0.05$ for comparison of TAH (overall) vs. SIADH group with each therapy: All therapies: Baseline $\left[\mathrm{Na}^{+}\right](\mathrm{BL}), \Delta_{\text {daily }}\left[\mathrm{Na}^{+}\right], \Delta_{24 h}\left[\mathrm{Na}^{+}\right]$, overly rapid correction. No active therapy: duration. Isotonic saline: $\left[\mathrm{Na}^{+}\right](\mathrm{BL}), \Delta_{\text {daily }}\left[\mathrm{Na}^{+}\right], \Delta_{24 h}\left[\mathrm{Na}^{+}\right]$, duration. Fluid restriction: $\Delta_{\text {daily }}\left[\mathrm{Na}^{+}\right]$. FR $+\mathrm{NS}: \Delta_{\text {daily }}\left[\mathrm{Na}^{+}\right]$, $\Delta_{24 h}\left[\mathrm{Na}^{+}\right]$. $p$ values $<0.05$ for comparison of immediate vs. delayed/no thiazide withdrawal in the TAH group: All therapies: $\mathrm{BL}, \Delta_{\text {daily }}\left[\mathrm{Na}^{+}\right], \Delta_{24 \mathrm{~h}}\left[\mathrm{Na}^{+}\right]$, duration, overly rapid correction. No active therapy: $\mathrm{BL}, \Delta_{\text {daily }}\left[\mathrm{Na}^{+}\right], \Delta_{24 \mathrm{~h}}\left[\mathrm{Na}^{+}\right]$, duration. Isotonic saline: $\mathrm{BL}, \Delta_{\text {daily }}\left[\mathrm{Na}^{+}\right], \Delta_{24 \mathrm{~h}}\left[\mathrm{Na}^{+}\right]$. Fluid restriction: $\mathrm{BL}$, $\Delta_{24 \mathrm{~h}}\left[\mathrm{Na}^{+}\right]$. Hypertonic saline: BL, $\Delta_{\text {daily }}\left[\mathrm{Na}^{+}\right], \Delta_{24 \mathrm{~h}}\left[\mathrm{Na}^{+}\right]$. $p$ values $<0.05$ for comparison of the various active therapies in TAH (overall) group: BL: No active treatment vs. all other therapies; NS vs. HS; FR vs. HS; FR + NS vs. HS. $\Delta_{\text {daily }}\left[\mathrm{Na}^{+}\right]$: No active treatment vs. all other therapies; NS vs. FR, FR + NS, HS; FR vs. FR + NS, HS. $\Delta_{24 h}\left[\mathrm{Na}^{+}\right]$: No active treatment vs. NS, HS, FR + NS; NS vs. FS HS; FR vs. FR + NS, HS; FR + NS vs. HS. Duration: No active treatment vs. all other therapies; NS vs. FR, FR + NS; FR vs. FR + NS. Overly rapid correction: not tested due to low numbers. IQR, interquartile range; TAH, thiazideassociated hyponatremia; SIADH, syndrome of inappropriate antidiuretic hormone secretion.

Finally, we attempted to identify possible SIADH patients within the TAH group by retrieving those who did not respond appropriately to thiazide withdrawal. Out of 29 patients, $11(38 \%)$ who were treated with early withdrawal but no active therapy did not improve (i.e., $\Delta\left[\mathrm{Na}^{+}\right]$ $\geq 5 \mathrm{mEq} / \mathrm{L}$ ). If they received saline in addition to thiazide withdrawal (thereby correcting possible subclinical hy- povolemia), still 24 of 79 (30\%) patients failed to improve. Thus, approximately one-third of TAH patients probably actually had SIADH.

At discharge, $86 \%$ of TAH patients were still hyponatremic, including $27 \%$ with $\left[\mathrm{Na}^{+}\right] \leq 130 \mathrm{mEq} / \mathrm{L}$ and $5 \%$ with $\left[\mathrm{Na}^{+}\right] \leq 125 \mathrm{mEq} / \mathrm{L}$. The median length of hospital stay (LOS) was not influenced by whether the thiazide 
Fig. 2. Success rate for $\Delta_{24 \mathrm{~h}}\left[\mathrm{Na}^{+}\right] 5 \mathrm{mEq} / \mathrm{L}$ but $\leq 12 \mathrm{mEq} / \mathrm{L}$ for distinct therapies in TAH. HS, hypertonic saline; NS, isotonic saline; FR, fluid restriction; withdrawal, immediate withdrawal of thiazide, no withdrawal; delayed or no withdrawal of thiazide. Data for tolvaptan not included in statistical testing due to low number. HS/ withdrawal vs. NS/no withdrawal: $p=0.041$. HS/withdrawal vs. FR/withdrawal: $p=$ 0.034 . HS/withdrawal vs. no therapy/withdrawal: $p=0.026$. HS/withdrawal vs. FR/no withdrawal: $p=0.005$. HS/withdrawal vs. no therapy/no withdrawal: $p<0.001 . n=$ number of patients

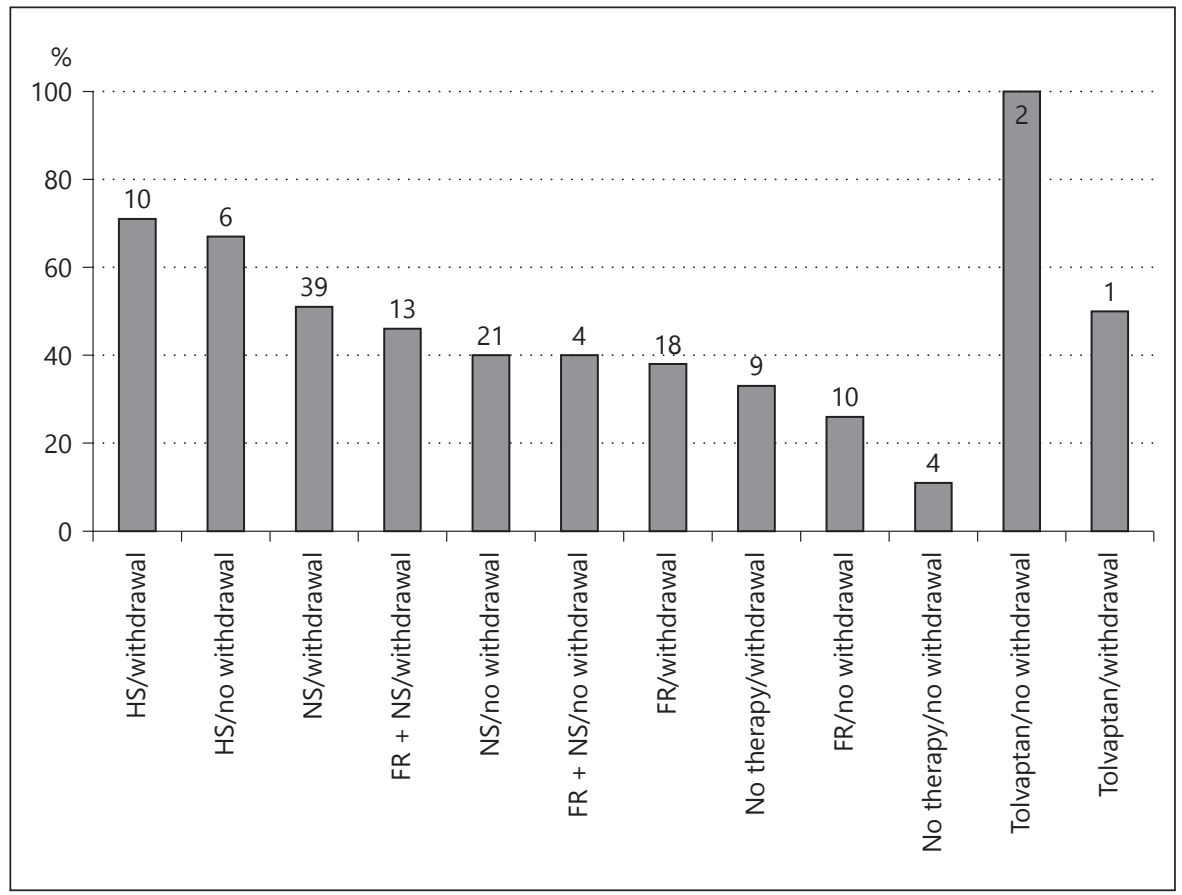

had been (6 [6] days) or had not been (6 [7] days) withdrawn. With 5 (3) days for no active therapy, 7 (5) days for NS, and 9 (13.5) days for HS, LOS likely reflects the severity of the cases rather than the effectiveness of the administered treatment option.

\section{Discussion and Conclusion}

The Hyponatremia Registry is the largest observational hyponatremia study to date and is unique in its examination of the diagnosis, treatment, and outcome of hyponatremia in diverse hospital settings. The current analysis focuses on the important subgroup of euvolemic TAH and, with 477 patients, this analysis represents the largest group of TAH ever studied. It should be noted that thiazides may well induce or aggravate hyponatremia in hypo- or hypervolemic patients; however, these patients were not included in this analysis.

With its focus on euvolemic hyponatremia, the HN Registry enrolled TAH and SIADH patients at a ratio of $1: 3$, thus emphasizing that TAH is a major disorder in the differential diagnosis of hyponatremia where SIADH is initially suspected. The high number of patients (773) who were erroneously diagnosed with SIADH by their treating physicians despite overt signs of hypovolemia and subsequently their exclusion after adjudication from the primary analysis group underline the need for a thorough diagnostic work-up. However, the recommended set of laboratory tests [23-26] including the SchwartzBartter criteria as well as cortisol and TSH were performed in only about $20 \%$ of all patients in either group. These findings demonstrate that the potentially deleterious impact of this disorder is often not appreciated and that the diagnostic management of hyponatremia in general is poor as has been shown repeatedly in the past [21, 27].

Since TAH does not necessarily signify TIH, we set out to select those TAH patients with a high likelihood of true TIH $(n=118)$ in order to identify diagnostically useful markers. Of note, statistical analysis of clinical characteristics (e.g., age and gender) as well as biochemical parameters in these 2 groups revealed no or only clinically insignificant differences, while both TAH and TIH were significantly distinct from the SIADH group. Fichman et al. [18] reported lower serum potassium and higher bicarbonate concentrations in TIH patients $(n=25)$ as compared to other hyponatremia etiologies including SIADH, but no discriminatory strategies have been established to date. Fenske et al. [28] reported on the superior value of fractional uric acid excretion in the differential diagnosis of hyponatremic patients who were treated with diuretics, but only 7 patients with TIH were included in this analysis. Using pairwise comparisons as well as univariate logistical 
regression analysis, we were able to show highly significant differences in various parameters, such as serum potassium, BUN, serum uric acid, urine sodium, urine osmolality, and empirically derived ratios such as urine $\left[\mathrm{Na}^{+}\right]$:serum creatinine or urine $\left[\mathrm{Na}_{+}\right]$:serum uric acid. Most of these findings are in line with the traditional idea of subclinical hypovolemia leading to vasopressin-dependent impairment of free water excretion. However, after performing multivariate analysis, none of the tested models using these parameters was found suitable for accurate diagnostic prediction. Thus, the ultimate separation of SIADH from TIH can be made only by evaluating the change in serum $\left[\mathrm{Na}^{+}\right]$ after withdrawal of the thiazide. The importance of this approach is further emphasized by the fact that, according to treatment response analyses, approximately $30 \%$ of TAH patients might in fact have SIADH.

Beyond its importance in determining the correct diagnosis, thiazide discontinuation constitutes the mainstay of TAH treatment $[25,26]$. However, in $30 \%$ of TAH patients, the thiazide was continued throughout the hospital stay and in $13 \%$, cessation was delayed by several days. Even among patients with severe hyponatremia, $27 \%$ remained on the drug. Overall, $10 \%$ of TAH patients were neither subjected to thiazide withdrawal nor received any active hyponatremia therapy. Hyponatremia frequently appears months or even years after the initiation of a thiazide diuretic, presumably as a consequence of acute development of a concurrent disorder, such as gastroenteritis or worsening heart failure, that led to the perturbation of a formerly stable steady state in which dietary intake matched water and solute losses [9]. Under these circumstances, the ensuing deterioration of osmotic homeostasis is often severe and potentially life threatening $[10,12]$. Hence, TAH should always be treated promptly even in mild or moderate cases in order to prevent progression $[25,26]$. To this end, eliminating the trigger by withdrawing the thiazide diuretic as early as possible is key to effective treatment. However, the results of the Registry infer that risk awareness among physicians in this context is low, and that correction of hyponatremia even with the simple maneuver of thiazide cessation is often not felt to be important.

In the overall group, immediate discontinuation of the thiazide in fact had a pronounced effect on serum $\left[\mathrm{Na}^{+}\right]$ with a $\Delta_{\text {daily }}\left[\mathrm{Na}^{+}\right]$and a $\Delta_{24 \mathrm{~h}}\left[\mathrm{Na}^{+}\right]$twice as high as in the group in which the drug was maintained. Similar effects were observed irrespective of whether drug withdrawal constituted the sole treatment or whether other active hyponatremia therapies were employed in addition to withdrawal $(p<0.05)$.
Hypertonic saline was the most effective active therapy with respect to $\Delta_{\text {daily }}\left[\mathrm{Na}^{+}\right]$and $\Delta_{24 \mathrm{~h}}\left[\mathrm{Na}^{+}\right]$, followed by FR + NS and NS; FR alone showed a markedly lower effectiveness, highlighting the value of correction of sodium deficits in TAH. This is of particular interest since FR, although not recommended in $\mathrm{TAH}$, is a frequently utilized therapy in euvolemic hyponatremia. As the pharmacological effect of the thiazide abates after withdrawal, rapid auto-correction of sodium levels is facilitated. Concomitant employment of HS can then easily lead to overly rapid correction, as shown here with a reported incidence of $21 \%$. Overly rapid correction can lead to severe neurological sequelae including osmotic demyelination syndrome (ODS), and more recent guidelines advocate lower limits than the ones used in this analysis $[25,26]$. Had we used these newer limits, an even higher rate of overly rapid correction would probably have been assessed. Although no cases of ODS were reported in the Registry, these findings clearly show that treatment of TAH with HS must be carried out with utmost caution and emphasize the importance of early diagnosis.

When compared to SIADH patients, overall $(p<0.001)$ as well as therapy-specific treatment effectiveness in the TAH group was significantly better. Not surprisingly, immediate drug discontinuation was the main factor accounting for this effect as this terminates the driving force for hyponatremia development and maintenance. Of note, despite superior effectiveness, overly rapid correction rates in the TAH group were markedly lower compared to the SIADH group for the overall treatment group (3.1\% vs. $10.2 \%)$ as well as all individual therapies except HS and tolvaptan.

The V2-receptor antagonist tolvaptan was used for initial therapy in 4 TAH patients, in 2 of whom the thiazide was stopped immediately. With a $\Delta_{24 \mathrm{~h}}\left[\mathrm{Na}^{+}\right]$of $8 \mathrm{mEq} / \mathrm{L}$ in 3 of these cases, this treatment appeared highly effective. Of course, the low number precludes statistical analysis and it is not known with certainty that these patients actually had SIADH rather than TIH with only coincidental use of thiazide. Even so, these findings do not support recent findings of vasopressin being suppressed in TIH [13]. To this end, prospective evaluation of V2-receptor antagonists in patients with confirmed $\mathrm{TIH}$ seems valuable in order to further elucidate the pathogenesis of TIH.

The clinician is faced with 2 major challenges in the management of TAH: (1) the need for rapid and effective therapy to avert complications of hyponatremia itself, and (2) the risk for overly rapid correction due to autocorrection following thiazide cessation. An increase of se- 
rum $\left[\mathrm{Na}^{+}\right]$of $\geq 5 \mathrm{mEq} / \mathrm{L}$ but $\leq 12 \mathrm{mEq} / \mathrm{L}$ can be viewed as a reasonable treatment goal for the first $24 \mathrm{~h}$. With a success rate of about $70 \%$, HS was superior to all other therapies irrespective of whether the thiazide had been stopped early. NS and FR + NS in combination with drug cessation showed success rates of about $50 \%$. HS and FR + NS were associated with the lowest treatment failure and ineffectiveness rates. conversely, the rate of overly rapid correction was significantly higher with immediate thiazide withdrawal. These findings suggest that one possible pragmatic treatment approach could be closely monitored administration of HS but without immediate withdrawal of the thiazide on day 1 , thereby reducing the risk of overly rapid correction. Immediate thiazide cessation in combination with NS or FR + NS could be an alternative, at least for less severe cases, while FR cannot be recommended.

The Hyponatremia Registry has a number of limitations, most of which derive from its observational design [22]. Although patients were subject to adjudication by experts, some uncertainty remains regarding the validity of the diagnoses TAH, TIH, and SIADH. Likewise, the high number of patients who were treated with other drugs that might also elicit hyponatremia contributes to this uncertainty. Furthermore, detailed statistical analysis was hampered by low numbers for some assessments and treatments, in particular overly rapid correction rates. However, since the study's intent was to capture "realworld" practice, this limitation does not detract from our observations on how TAH is currently managed. As in other hyponatremia studies, numerical changes of $\left[\mathrm{Na}^{+}\right]$ were used as the primary measure of effectiveness; neither pre- or post-treatment symptoms nor clinical outcome after therapy was reported reliably enough in the Registry to assess benefits other than a change in $\left[\mathrm{Na}^{+}\right]$. Of note, the numbers of TAH with individual thiazide congeners cannot be interpreted as incidence rates, since data on patients receiving a thiazide-containing medication but without hyponatremia were not collected in the Hyponatremia Registry. Of note, $50 \%$ of all TAH patients received other potential hyponatremia-inducing drugs concomitantly.

In conclusion, despite the high prevalence of hyponatremia [29-31] and published guidance on its diagnosis and treatment $[25,26]$, numerous shortcomings in current management of hyponatremia in general and TAH in particular are evident. Although many highly significant differences exist with regard to clinical and biochemical characteristics, we could not identify a specific diagnostic strategy that reliably distinguished TIH from

Thiazide-Associated Hyponatremia
SIADH. Early withdrawal of the thiazide diuretic is crucial for resolving hyponatremia, but in many patients, the medication is maintained. Furthermore, $18 \%$ of TAH patients do not receive any treatment for hyponatremia at all, and a considerable number of patients are discharged with unresolved hyponatremia. NS and FR are the 2 most frequently used therapies but only moderately effective in increasing serum $\left[\mathrm{Na}^{+}\right]$. In contrast, $\mathrm{HS}$ and $\mathrm{FR}+\mathrm{NS}$ exhibited the highest success rates but are utilized less frequently. While overly rapid correction rate is low compared to SIADH patients for most therapies, aggressive treatment with HS in combination with thiazide discontinuation is associated with overly rapid correction rates of more than $20 \%$, which is a particular danger, since $\mathrm{TAH}$ is a cause of chronic rather than acute hyponatremia and overly rapid correction carries a high presumed risk of ODS. We conclude that there is a need to focus educational efforts on (1) increased awareness with respect to the impact of $\mathrm{TAH},(2)$ optimal diagnostic approaches, (3) the importance of drug withdrawal, and (4) the appropriate use of saline solutions for treatment.

\section{Acknowledgments}

We thank Alpesh Amin, MD, Jun Chiong, MD, Joseph Dasta, PharmD, Paul Hauptman, MD, and Samuel Sigal, MD for their participation in the US Steering Committee for the Hyponatremia Registry, with funding by Otsuka. We thank Stephen Ball, MBBS, PhD, FRCP, Newcastle University, Newcastle, United Kingdom, Jean-Philippe Haymann, MD, Hôpital Tenon, Paris, France, Gudmundur Johannsson, MD, PhD, University of Göteborg, Sweden, Jens Otto Lunde Jørgensen, MD, Aarhus University Hospital, Aarhus, Denmark, Alessandro Peri, MD, University of Florence, Italy, and Esteban Poch, MD, University of Barcelona, Spain for their participation on the European Steering Committee for the Hyponatremia Registry, with funding by Otsuka. Statistical analysis was performed by Ms. Ingrid Becker, Institute of Medical Statistics, Informatics and Epidemiology (IMSIE), University of Cologne, Germany. Jamie Jarecki-Smith of Otsuka provided continuing support for reviewing data entered in preparation for analysis and for accuracy. Funding for study design, conduct, and study oversight was provided by Otsuka America Pharmaceutical, Inc.

\section{Disclosure Statement}

Dr. V. Burst is a consultant and his institution received research support from Otsuka in his role as Hyponatremia Registry. He also received travel support and fees for data-review activities, as well as serving on a speakers' bureau for Otsuka. Dr. F. Grundmann and Dr. T. Kubacki have received travel support. Dr. A. Greenberg is a consultant and his institution received research support for his

Am J Nephrol 2017;45:420-430

DOI: $10.1159 / 000471493$ 
role as investigator for the Hyponatremia Registry from Otsuka. $\mathrm{He}$ also received travel support and fees for data review activities, as well as, serving on a speakers' bureau for Otsuka. Additionally, he has acted as a consultant and has received fees for expert testimony from Cornerstone. Ms I. Becker is a statistician of the IMSIE and has nothing to declare. Dr. D. Rudolf is an Otsuka employee. Dr. J. Verbalis is a consultant, and his institution received research support for his role as investigator for the Hyponatremia Registry and for investigator-sponsored trials from Otsuka. He has received travel support and fees for data-review activities and educational presentation development, as well as serving on a speakers' bureau for Otsuka. He is also a consultant and received fees for expert testimony from Cardiokine. No payment was provided to any author for the development of the manuscript.

\section{References}

1 Freis ED, Wanko A, Wilson IM, Parrish AE: Treatment of essential hypertension with chlorothiazide (diuril); its use alone and combined with other antihypertensive agents. J Am Med Assoc 1958;166: 137-140.

2 Prevention of stroke by antihypertensive drug treatment in older persons with isolated systolic hypertension. Final results of the Systolic Hypertension in the Elderly Program (SHEP). SHEP Cooperative Research Group. JAMA 1991;265:3255-3264.

3 Byatt CM, Millard PH, Levin GE: Diuretics and electrolyte disturbances in 1000 consecutive geriatric admissions. J R Soc Med 1990; 83:704-708.

4 Clayton JA, Rodgers S, Blakey J, Avery A, Hall IP: Thiazide diuretic prescription and electrolyte abnormalities in primary care. Br J Clin Pharmacol 2006;61:87-95.

5 Leung AA, Wright A, Pazo V, Karson A, Bates DW: Risk of thiazide-induced hyponatremia in patients with hypertension. Am J Med 2011;124:1064-1072.

6 Rodenburg EM, Hoorn EJ, Ruiter R, et al: Thiazide-associated hyponatremia: a populationbased study. Am J Kidney Dis 2013;62:67-72.

7 Olsson K, Ohlin B, Melander O: Epidemiology and characteristics of hyponatremia in the emergency department. Eur J Intern Med 2013;24:110-116.

8 Elliott WJ, Weber RR, Murphy MB: A doubleblind, randomized, placebo-controlled comparison of the metabolic effects of low-dose hydrochlorothiazide and indapamide. J Clin Pharmacol 1991;31:751-757.

9 Barber J, McKeever TM, McDowell SE, et al: A systematic review and meta-analysis of thiazide-induced hyponatraemia: time to reconsider electrolyte monitoring regimens after thiazide initiation? Br J Clin Pharmacol 2015; 79:566-577.

10 Ashraf N, Locksley R, Arieff AI: Thiazide-induced hyponatremia associated with death or neurologic damage in outpatients. Am J Med 1981;70:1163-1168.
11 Sonnenblick M, Friedlander Y, Rosin AJ: Diuretic-induced severe hyponatremia. Review and analysis of 129 reported patients. Chest 1993;103:601-606.

12 Friedman E, Shadel M, Halkin H, Farfel Z: Thiazide-induced hyponatremia. Reproducibility by single dose rechallenge and an analysis of pathogenesis. Ann Intern Med 1989; 110:24-30.

13 Frenkel NJ, Vogt L, De Rooij SE, Trimpert C, Levi MM, Deen PM, van den Born BJ: Thiazide-induced hyponatraemia is associated with increased water intake and impaired urea-mediated water excretion at low plasma antidiuretic hormone and urine aquaporin-2. J Hypertens 2015;33: 627-633.

14 Cesar KR, Magaldi AJ: Thiazide induces water absorption in the inner medullary collecting duct of normal and Brattleboro rats. Am J Physiol 1999;277:F756-F760.

$15 \mathrm{Kim}$ GH, Lee JW, Oh YK, et al: Antidiuretic effect of hydrochlorothiazide in lithium-induced nephrogenic diabetes insipidus is associated with upregulation of aquaporin-2, $\mathrm{Na}-\mathrm{Cl}$ co-transporter, and epithelial sodium channel. J Am Soc Nephrol 2004;15:28362843.

16 Spital A: Diuretic-induced hyponatremia. Am J Nephrol 1999;19:447-452.

17 Decaux G, Schlesser M, Coffernils M, Prospert F, Namias B, Brimioulle S, Soupart A: Uric acid, anion gap and urea concentration in the diagnostic approach to hyponatremia. Clin Nephrol 1994;42:102-108.

18 Fichman MP, Vorherr H, Kleeman CR, Telfer N: Diuretic-induced hyponatremia. Ann Intern Med 1971;75:853-863.

19 Fuisz RE, Lauler DP, Cohen P: Diuretic-induced hyponatremia and sustained antidiuresis. Am J Med 1962;33:783-791.

20 Sonnenblick M, Rosin AJ: Significance of the measurement of uric acid fractional clearance in diuretic induced hyponatraemia. Postgrad Med J 1986;62:449-452.
21 Greenberg A, Verbalis JG, Amin AN, et al: Current treatment practice and outcomes. Report of the hyponatremia registry. Kidney Int 2015;88:167-177.

22 Hauptman PJ, Greenberg A, Verbalis JG, Amin A, Sigal S, Chiong J: Design of a prospective, multinational registry to evaluate patients hospitalized with hyponatremia: the HN Registry. Open Access J Clin Trials 2013;5:93-100.

23 Bartter FC, Schwartz WB: The syndrome of inappropriate secretion of antidiuretic hormone. Am J Med 1967;42:790-806.

24 Schwartz WB, Bennett W, Curelop S, Bartter FC: A syndrome of renal sodium loss and hyponatremia probably resulting from inappropriate secretion of antidiuretic hormone. Am J Med 1957;23:529-542.

25 Spasovski G, Vanholder R, Allolio B, et al: Clinical practice guideline on diagnosis and treatment of hyponatraemia. Nephrol Dial Transplant 2014;29(suppl 2): i1-i39.

26 Verbalis JG, Goldsmith SR, Greenberg A, Korzelius C, Schrier RW, Sterns RH, Thompson CJ: Diagnosis, evaluation, and treatment of hyponatremia: expert panel recommendations. Am J Med 2013;126:S1-S42.

27 Verbalis J, Greenberg A, Burst V, et al: Diagnosing and treating the syndrome of inappropriate antidiuretic hormone secretion. Am J Med 2016;129:537.e9-537.e23.

28 Fenske W, Stork S, Koschker AC, Blechschmidt A, Lorenz D, Wortmann S, Allolio B: Value of fractional uric acid excretion in differential diagnosis of hyponatremic patients on diuretics. J Clin Endocrinol Metab 2008; 93:2991-2997.

29 Cumming K, Hoyle GE, Hutchison JD, Soiza RL: Prevalence, incidence and etiology of hyponatremia in elderly patients with fragility fractures. PLoS One 2014;9:e88272.

30 Hawkins RC: Age and gender as risk factors for hyponatremia and hypernatremia. Clin Chim Acta 2003;337:169-172.

31 Upadhyay A, Jaber BL, Madias NE: Incidence and prevalence of hyponatremia. Am J Med 2006;119:S30-S35. 